\title{
Graft Success and Hearing Results between Cartilage Island Graft and Temporal Muscle Fascia Graft Myringoplasty
}

\author{
Ayse Secil Kayali Dinc, Melih Cayonu, Suleyman Boynuegri, Muammer Melih Sahin, Betul Paksoy and Adil Eryilmaz
}

Department of Otorhinolaryngology and Head Neck Surgery, Ankara Numune Training and Research Hospital, Ankara, Turkey

\begin{abstract}
Objective: To compare the graft success and hearing results in patients who underwent cartilage island graft $(\mathrm{ClG})$ myringoplasty and temporal muscle fascia graft (TFG) myringoplasty.

Study Design: Retrospective clinical study.

Place and Duration of Study: Ankara Numune Training and Research Hospital, Otolaryngology Clinic, Ankara, from January 2013 to January 2018.

Methodology: Patients who underwent cartilage island graft myringoplasty and temporal muscle graft myringoplasty for chronic non-suppurative otitis media were inducted. Age, gender, preoperative audiologic examination results, postoperative audiologic examination, perforation site, graft material, preoperative microscopic examination and graft success were documented.

Results: A total of 116 patients were included in the study. The mean age of the patients was $35 \pm 15.3$ years. Fifty-four patients were females and 62 were males. Temporal muscle fascia graft was applied to $68(58.6 \%)$ patients, while cartilage graft was applied to $48(41.4 \%)$ patients. The success rate of graft was found to be $80.2 \%$ (55 cases with graft success) in TFG; whereas, this rate was found to be $93.8 \%$ (45 cases with graft success) in CIG group. Cartilage island graft material had a better graft success in terms of graft endurance $(p=0.048)$. There was no statistically significant difference between the two graft materials in terms of postoperative hearing success $(p=0.29)$.

Conclusion: Cartilage island grafts can be preferable for myringoplasty operations.
\end{abstract}

Key Words: Myringoplasty, Graft, Cartilage, Temporal muscle, Fascia, Success rate, Chronic non-suppurative otitis media.

How to cite this article: Dinc ASK, Cayonu M, Boynuegri S, Sahin MM, Paksoy B, Eryilmaz A. Graft success and hearing results between cartilage island graft and temporal muscle fascia graft myringoplasty. J Coll Physicians Surg Pak 2020; 30(1):33-36.

\section{INTRODUCTION}

Chronic otitis media causes permenant damage of tympanic mymbrane with structural changes in the middle ear. ${ }^{1}$ In those patients, tympanic membrane perforation, ear discharge and conductive hearing loss are observed. The ear discharge lasting more than three months is indicative of the chronicity of otitis media. In time, sensorineural hearing loss can be added to the conductive hearing loss in patients. Patients who do not have ear discharge are labelled as having chronic nonsuppurative otitis media.

In chronic non-suppurative otitis media, the aim is to improv the middle ear mucosa with the closure of the perforation in the eardrum. The procedure is made without touching the ossicle, called myringoplasty, is a common procedure in otological practice. It is done to eliminate the infection and improve the hearing through

Correspondence to: Ayse Secil Kayali Dinc, Department of Otorhinolaryngology and Head Neck Surgery, Ankara Numune Training and Research Hospital, Hacettepe, Talatpasa Blv No:44, 06230 Altindag, Ankara, Turkey

E-mail: secilkayali81@yahoo.com

Received: May 03, 2019; Revised: August 07,2019;

Accepted: September 11, 2019 miringoplasty, but also to give the patients the chance to perform water sports. ${ }^{2-7}$

In myringoplasty, temporal muscle fascia and cartilage grafts can be used as graft material. Although satisfactory results are obtained in miringoplasty with temporal muscle fascia graft, this technique can be failed in cases with Eustachian tube dysfunction, adhesive otitis and total/subtotal perforations. Therefore, cartilage island graft is preferred due to resistance to infection, retraction, and resorption. ${ }^{2-7}$

There were many studies including the comparison of cartilage graft and temporal muscle facia graft. However, in those studies cartilage grafting techniques might varies according to the cases such as, palizade, butterfly, island, full thickness or sliced cartilage grafts.2-7

Thus, the aim of this study was to compare the results of myringoplasty using temporal muscle fascia graft (TFG) and composite cartilage island graft (CIG), which was prepared from the tragal cartilage and had a wider perichondrium than the island of cartilage, in terms of graft success and hearing.

\section{METHODOLOGY}

Patients who underwent CIG and TFG for chronic nonsuppurative otitis media in the Ankara Numune Training 
and Research Hospital Otolaryngology Clinic between 2013-2018 were included in this retrospective clinical study. Demographic data of the patients (age, gender, identification numbers, and telephones), preoperative audiological examination results, postoperative audiological examination, location and type of perforation, graft material used in operation, preoperative microscopic examination and graft success were documented.

Patients undergoing mastoidectomy and ossicle repair were excluded from the study. Only patients with myringoplasty were included in this study. All investigations were performed in accordance with the Helsinki Declaration on biomedical studies involving human subjects, and informed consents were obtained from all study subjects. The study was approved by the local Institutional Review Board (E-19-2643).

All the patients included in this study retrospectively were operated via post auricular insicion under general anesthesia. Island cartilage grafts were prepared from tragal cartilage in all cases and the perichondrium of the one side of the cartilage was opened; whereas, the perichondrium left attached to the cartilage at the other side of the island graft. As a result, an island cartilage graft with a wider perichondrium was obtained. Temporal muscle facia graft was obtained via the same postauricular insicion. Both the temporal muscle facia graft and the island cartilage graft were positioned in same manner, as called underlayed grafting technique.

Continuous variables were expressed as mean \pm SD. Categorical variables were expressed in percentages. Student's t-test or Chi-square test was used wherever appropriate. A p-value of $<0.05$ was considered significant. SPSS statistical software (SPSS for Windows, version 16.0; SPSS Inc., Chicago, IL, USA) was used for statistical evaluation.

\section{RESULTS}

Of the 116 patients included in the study, 62 (53.4\%) were males and $54(46.6 \%)$ were females. The mean age of the patients was $35 \pm 15.3$ (06 - 66) years. The operation was performed on the right ear of 59 patients and on the left ear of 57 patients. In the microscopic examination, central perforation was observed in 88 $(75.9 \%)$ patients, while marginal perforation was seen in $13(11.2 \%)$ patients; and retracted tympanic membrane was seen in $15(12.9 \%)$ patients. Given the location of tympanic membrane pathology, pars tensa was observed in $90(77.6 \%)$ patients, while attic was seen in $13(11.2 \%)$ patients, and total tympanic membrane pathology was observed in $13(11.2 \%)$ patients. Temporal muscle fascia graft was applied to 68 (58.6\%) patients, while cartilage graft was applied to $48(41.4 \%)$ patients. The success rate of graft was found to be $80.2 \%$ (55 cases with graft success) in TFG; whereas, this rate was found to be $93.8 \%$ (45 cases with graft success) in CIG
Table I: Preoperative and postoperative hearing results according to the graft materials.

\begin{tabular}{l|c|c|c}
\hline & $\begin{array}{c}\text { Temporal } \\
\text { muscle fascia } \\
\text { graft }\end{array}$ & $\begin{array}{c}\text { Cartilage } \\
\text { graft }\end{array}$ & p-value* \\
\hline Preoperative bone hearing results & $14 \pm 9.5$ & $15 \pm 11$ & 0.85 \\
Preoperative air hearing results & $39 \pm 12$ & $40 \pm 14$ & 0.57 \\
Postoperative bone hearing results & $14.5 \pm 11$ & $15 \pm 11$ & 0.84 \\
Postoperative air hearing results & $30 \pm 15$ & $36 \pm 18$ & 0.19 \\
Delta air hearing results & $-8.27 \pm 13.5$ & $-4.7 \pm 13$ & 0.29 \\
\hline
\end{tabular}

*Independent samples t-test of groups.

group. Cartilage island graft material had a better graft success in terms of graft endurance $(p=0.048)$.

The hearing results of all patients undergoing surgery were evaluated. The mean airway values of all patients were $40 \pm 14$ in the preoperative period, while the mean airway values were $39 \pm 12$ years in the postoperative period. There was no statistically significant difference between the two graft materials in terms of postoperative hearing success $(p=0.29$, Table I).

TFG was often preferred for pars tensa perforations (90 patients with pars tensa perforation; temporal muscle fascia grafts were applied in 62 patients, and CIG was applied to 28 patients, $(p<0.001)$.

CIG was usually preferred for attic perforations. In 13 attic perforation, 11 patients underwent $\mathrm{CIG}$ and two patients underwent TFG) $(p<0.001)$.

\section{DISCUSSION}

In myringoplasty, temporal muscle fascia cartilage, fat, perichondrium, periosteum, vein, skin and dura graft materials can be used. However the majority of the studies were performed with using temporal muscle facia or cartilage greft types.2-8 Only the perforated tympan membrane is repaired in the miringoplasty. Different tympanoplasty techniques are applied for the pathologies in the ossicular, middle ear and mastoid. Repair of the tympanic membrane is intended for an intact membrane and an optimal hearing recovery. 8 In a study by Bhat, a $59 \%$ improvement in hearing was observed and myringoplasty was recommended for patients with perforated tympanic membrane and hearing loss. ${ }^{9}$

In myringoplasty, the graft may be overlayed or underlaid according to the lateral or medial placement of the tympanic membrane. Underlay technique defined by Austin and Shea is one of the most successful techniques and is widely used. 10 In a study by Gersdoff et al., it was shown that the use of graft as overlay or underlay was not statistically significant. ${ }^{11}$ In this study, grafts were underlaid.

Temporal muscle fascia graft has been used for a long time due to its easy availability in the operation area. Temporal muscle fascia is very resistant to infection. ${ }^{12}$ Temporal muscle fascia graft does not restrict the 
vibration of the sound waves reaching the tympanic membrane. Membranous materials provide $85-90 \%$ success in a normally ventilated middle ear. ${ }^{13}$ Adhesive ears are less successful in smoking patients, patients with disease in two ears, and if all membranes are perforated and tubal dysfunction is available. 14

Although there are high success rates with temporal muscle fascia graft, poor results may be obtained when graft success decreases in late postoperative period, and in case of perforations in anterior and wide perforations. ${ }^{15,16}$ Considering the literature, the success rates of graft change in operations performed using temporal muscle fascia. ${ }^{17}$

Graft success rates were found to be $82 \%$ in temporal muscle fascia graft in a meta-analysis by Jalali et al.2 In this study, the success rate is $80.2 \%$. These results were consistent with the results of other studies in the literature.

According to a study, the cartilage graft provides a stable tympanic membrane, reducing the need for retraction and revision surgery, and suggested that it should be preferred for the repair of perforations in complex cases. ${ }^{18}$ Because of its high mechanical stability, it gives more successful results than the temporal muscle fascia graft in the adhesive ears and wide perforations with tubal dysfunction. ${ }^{19}$ Due to its durable structure, cartilage has been an important option for its use in wide perforations. In a study by Kapusuz et al., the success rate in myringoplasties using tragal cartilage graft was $98 \%$, while the success rate in myringoplasties using temporal muscle fascia was found to be $80 \% .20$ In this study, the success of cartilage graft was $93.8 \%$. However, the increased mass and stiffness of the tympanic membrane together with the use of cartilage graft may cause high acoustic impedance, which changes the acoustic transfer properties. ${ }^{21}$ Yetiser et al. showed in his study that voice transmission is reduced with the thickness and width of the graft in cartilage graft. 22 There are also studies showing that acoustic transfer properties are the same as normal tympanic membrane when cartilage thickness is less than or equal to $0.5 \mathrm{~mm} .{ }^{14}$ In the study by Demirpehlivan et al., it was found that cartilage graft was an effective graft material in terms of success and it did not have any negative effect on hearing results. 8

Given the hearing results, Yung et al. showed in his study that the use of temporal muscle fascia on hearing had more positive effects on hearing compared to patients who used carotid. 23 Vashishth et al. found that the hearing results of the patients using cartilage grafts were better than those using the temporal muscle fascia graft.24 In a study by Atan et al., it was found that the patients using cartilage graft and temporal muscle fascia grafts were found to have similar hearing gain. ${ }^{7}$ In this study, the hearing gains of CIG and TFG were similar.

The limitation of this study is that it is done retrospectively; and low number of participants might be another limitation, considering the high frequency of myringoplasty surgery in otologic practice. Moreover, different perforation types were included in this study groups, so the participants were not unique in terms of tympanic membrane perforation types.

\section{CONCLUSION}

Island cartilage grafts can be a better preference with endurance and hearing results when compared to temporal facia grafts.

\section{ETHICAL APPROVAL:}

Ethics approval was received for this study from Ankara Numune Training and Research Hospital/E-19-2643.

\section{PATIENTS' CONSENT:}

Informed consents were obtained from all participants.

\section{CONFLICT OF INTEREST:}

Authors declared no conflict of interest.

\section{AUTHORS' CONTRIBUTION:}

ASKD, MC: Contributed to study design, data acquisition, data analysis, and paper writing.

SB, MMS, BP: Contributed to data acquisition, paper writing. $A E$ : Contributed to study design, data analysis.

\section{REFERENCES}

1. Telian SA, Schmalbach CE, Chronic otitis media, In: Snow JB, Ballenger JJ, eds. Ballenger's otorhinolaryngology head and neck surgery spain. BC Decker 2003; 261-93.

2. Jalali MM, Motasaddi M, Kouhi A, Dabiri S, Soleimani R. Comparison of cartilage with temporalis fascia tympanoplasty a meta-analysis of comparative studies. Laryngoscope 2017; 127:2139-48.

3. Khalilullah S, Shah SP, Yadav D, Shrivastav RP, Bhattarai H. Comparison of results of graft uptake using tragal cartilage perichondrium composite graft versus temporalis fascia in patients undergoing surgery for chronic otitis media - squamous type. Head Face Med 2016; 12:26.

4. Khan MM, Parab SR. Comparative study of sliced tragal cartilage and temporalis fascia in type I tympanoplasty. $J$ Laryngol Otol 2015; 129:16-22.

5. Yang Z, Wu X, Chen X, Huang Y, Fang L, Li X, et al. Comparison of type I tympanoplasty with acellular dermal allograft and cartilage perichondrium. Acta Otolaryngol 2019; 139:833-6.

6. Karela M, Berry S, Watkins A, Phillipps JJ. Myringoplasty surgical outcomes and hearing improvement: Is it worth performing to improve hearing? Eur Arch Otorhinolaryngol 2008; 265: 1039-42.

7. Atan D, Yamur AR, Ensari S, Ikinciogullari A, Çetin MA, Özcan KM, et al. Miringoplastide greft materyali olarak temporal adele fasyasi ve kikirdak kullaniminin cerrahi basariya etkisi. KBB Ve BBC Dergisi 2015; 23:97-101.

8. Demirpehlivan A, Onal K, Arslanoglu S, Songu M, Ciger E, Can N. Comparison of different tympanic membrane reconstruction techniques in type I tympanoplasty. Eur Arch Otorhinolaryngol 2011; 268:471-4. 
9. Bhat NA, De R. Retrospective analysis of surgical outcome symptom changes and hearing improvement following myringoplasty. J Otolaryngol 2000; 29:229-32.

10. Athanasiadis-Sismanis A. Tympanoplasty tympanic membrane repair glasscock-shambaugh surgery of the ear 6th ed shelton. Peoples Medical Publishing House 2010; 465-88.

11. Parida PK, Nochikattil SK, Surianarayanan G, Saxena SK, Ganesan S. A comparative study of temporalis fascia graft and vein graft in myringoplasty. Indian $\mathrm{J}$ Otolaryngol Head Neck Surg 2013; 65:569-74.

12. Tatlipinar A, Gökçeer T, Tuncel A. Timpanoplastide temporal kas fasya greftinin basarisini etkileyen faktörler. KBB Forum 2010; 9:88-94.

13. Onal K, Uguz MZ, Kazikdas KC, Gursoy ST, Gokce H. A multivariate analysis of otological, surgical and patient-related factors in determining success in myringoplasty. Clin Otolaryngol 2005; 30:115-20.

14. Mürbe $D$, Zahnert $T$, Bornitz $M$, Hüttenbrink KB. Acoustic properties of different cartilage reconstruction techniques of the tympanic membrane. Laryngoscope 2002; 112:1769-76.

15. Dornhoffer, John. Cartilage tympanoplasty indications, techniques and outcomes in a 1,000 patient series. Laryngoscope 2003; 113:1844-56.

16. Caylan R, Titiz A, Falcioni M, De Donato G, Russo A, Taibah A, et al. Myringoplasty in children factors influencing surgical outcome. Otolaryngol Head Neck Surg 1998; 118:709-13.
17. Mishiro $Y$, Sakagami M, Takahashi $Y$, Kitahara T, Kajikawa H, Kubo T. Tympanoplasty with and without mastoidectomy for noncholesteatomatous chronic otitis media. Eur Arch Otorhinolaryngol 2001; 258:13-5.

18. Shekharappa MK, Siddappa SM. Cartilage Myringoplasty an Ideal grafting technique for complex perforations. J Clin Diagn Res 2017; 11:MC06-MC8.

19. Dornhoffer JL. Surgical management of the atelectatic ear. $A m$ J Otol 2000; 21:315-21.

20. Kapusuz Z, Saydam L, Sakallioglu L, Düzer S. Tip 1 timpanoplastide fasya ve kartilaj greft kullanimi sonuçlari. Bozok Tip Dergisi 2011; 1:1-6.

21. Schöttke H, Hartwein J, Pan HW. Einfluß unterschiedlicher transplantatmaterialien bei der tympanoplastik Typ 1 auf den schalldruckpegel im gehörgang. Oto-Rhino-Laryngologia Nova 1992; 2:318-20.

22. Yetiser $\mathrm{S}$, Hidir Y. Temporalis fascia and cartilage-perichondrium composite shield grafts for reconstruction of the tympanic membrane. Ann Otol Rhinol Laryngol 2009; 118:570-4.

23. Yung M, Vivekanandan S, Smith P. Randomized study comparing fascia and cartilage grafts in myringoplasty. Ann Otol Rhinol Laryngol 2011; 120:535-41.

24. Vashishth A, Mathur NN, Choudhary SR, Bhardwaj A. Clinical advantages of cartilage palisades over temporalis fascia in type I tympanoplasty. Auris Nasus Larynx 2014; 41:422-7. …도... 